\title{
"Measurement and Analysis of Indian Road Drive Cycles for Efficient and Economic Design of HEV Component"
}

\author{
Mr.Vishal Parekh ${ }^{1}$, Dr.Varshaben Shah ${ }^{2}$ \\ Power Electronics and Electronic Drive, Research Head, ASPERO Research, India ${ }^{l}$ \\ Electrical Department, Prof. SVNIT, India ${ }^{2}$
}

\begin{abstract}
Drive cycle pattern is different for different countries which depends on their traffic density, road condition and driver discipline. Drive cycle influences HEV`s components design, sizing and their ratings. Standard drive cycle data doesn't reveal much information to determine efficient and economic design of HEV`s components. In this research paper measurement and analysis of real time Indian road drive cycles (IRDC) are carried out for urban roads, state highway, national highway and express Highway where vehicles have their most run. Real time drive cycle data will expose impact of driver's skills, traffic, road conditions and short acceleration / deceleration period, which can be represented on drive cycle chart. Analysis of IRDC in terms of rate of acceleration and deceleration, top speed, average speed with road length and analysed mathematically to find energy and power required for acceleration, normal operation and energy harvested during deceleration. Based on information from IRDC HEV`s components initial size are estimated. Initial estimated size is optimized to make HEV`s components design more efficient and economic. Teaching and learning based optimization algorithm (TLBO) and Multi objective genetic algorithm (MOGA) are used to optimize HEV`s components. Constraint of optimization algorithm are like engine and motor rating should be selected such that it has effective top speed with enough acceleration capability and can run enough distance to reach destination according to Indian urban, state, national and express highway pattern where cities are very closed compared with other countries and its regeneration component design should able to harvest maximum deceleration energy. For economic operation of HEV's, running cost in terms of Rs. / $\mathrm{Km}$. should be minimum.
\end{abstract}

Keywords: Indian Road Drive Cycle, Hybrid Electric Vehicle Component, Efficient and Economic, Analysis of Drive Cycle, Drive Cycle and HEV

\section{NOMENCLATURE}

\begin{tabular}{|c|c|c|c|}
\hline $\mathrm{V}_{\mathrm{OC}}$ & Battery open circuit voltage (V) & $\operatorname{Exp}(\mathrm{t})$ & Exponential zone voltage (V) \\
\hline & & $d w$ & Change in watt (W) \\
\hline $\mathrm{E}_{\mathrm{o}}$ & Battery constant voltage (V) & $\overline{d t_{(<0)}}$ & \\
\hline $\mathrm{R}$ & Internal resistance (Ohm) & $\mathrm{V}_{\text {charge }}$ & Charging voltage (V) \\
\hline $\mathrm{i}$ & Battery current (Amp) & $V_{\text {total }}$ & Total voltage (V) \\
\hline $\mathrm{K}$ & Polarization constant (V/Ah) & $C_{c c}$ & Charge constant \\
\hline $\begin{array}{l}\text { Q } \\
\text { it }\end{array}$ & $\begin{array}{c}\text { Battery capacity }(\mathrm{Ah}) \\
\text { Actual battery charge (Ah) }\end{array}$ & $\mathrm{Q}_{\mathrm{ut}}$ & Total charge of battery (Ah) \\
\hline
\end{tabular}




\begin{tabular}{|c|c|c|c|}
\hline $\mathrm{Q}_{\mathrm{u}}$ & Actual charge of battery (Ah) & $\mathrm{M}_{\mathrm{v}}$ & $\begin{array}{l}\text { (CG) of Car and Rear Wheel } \\
\text { Mass of Vehicle }\end{array}$ \\
\hline $\mathrm{K}$ & SOC level (\%) & & \\
\hline HP & Horse Power & $\begin{array}{l}\mathrm{g} \\
\alpha\end{array}$ & $\begin{array}{l}\text { Gravitational Force } \\
\text { Slant Angle of Road }\end{array}$ \\
\hline W & Watt & $\mathrm{h}_{\mathrm{g}}$ & Height of CG of Car \\
\hline $\mathrm{T}$ & Torque & $\begin{array}{l}\text { Wf } \\
\text { Fr }\end{array}$ & $\begin{array}{l}\text { Normal Load On Front Excel } \\
\text { Frictional Constant }\end{array}$ \\
\hline $\mathrm{P}$ & Power & & \\
\hline $\mathrm{V}$ & Voltage & $r_{g}$ & Effective Tier Radius \\
\hline $\mathrm{I}$ & Current & $\mathbf{M}_{\text {Meani }}$ & $\begin{array}{l}\text { Mean of Drive cycle parameters of } i^{\text {th }} \\
\text { number population }\end{array}$ \\
\hline $\mathrm{N}_{\mathrm{m}}$ & Mechanical Speed & $\mathrm{M}_{\mathrm{N}}$ & New Drive Cycle Parameter \\
\hline $\mathrm{N}$ & Turn of winding & $\mathrm{M}_{\mathrm{o}}$ & Old Drive Cycle Parameter \\
\hline $\mathrm{R}_{\mathrm{r} 0}$ & Rotor Diameter & $\mathrm{T}_{\mathrm{F}}$ & Teaching Factor \\
\hline $\mathrm{L}_{\mathrm{st}}$ & Stack Length & $\mathrm{M}_{\mathrm{i}}, \mathrm{M}_{\mathrm{j}}$ & $\begin{array}{c}\text { Drive cycle Parameter of } i^{\text {th }} \text { and } j^{\text {th }} \\
\text { number }\end{array}$ \\
\hline$\mu_{0}$ & Absolute Permeability & SOC & State of Charge \\
\hline$\mu_{\mathrm{r}}$ & Relative Permeability & $\begin{array}{l}\text { HEV } \\
\text { IC }\end{array}$ & $\begin{array}{l}\text { Hybrid Electric Vehicle } \\
\text { Internal Combustion }\end{array}$ \\
\hline $\mathrm{C}_{\Phi}$ & Flux - Construction Factor & $\begin{array}{c}\text { GA } \\
\text { MOGA }\end{array}$ & $\begin{array}{c}\text { Genetic Algorithm } \\
\text { Multi Objective Genetic Algorithm }\end{array}$ \\
\hline$A_{m}$ & Magnate Pole Area & TLBO & $\begin{array}{c}\text { Teaching and Learning Based } \\
\text { Optimization }\end{array}$ \\
\hline $\mathrm{A}_{\mathrm{g}}$ & Air Gap Area & IRDC & Indian Road Drive Cycle \\
\hline $1_{\mathrm{m}}$ & Length Of Magnet & & \\
\hline
\end{tabular}

\section{Introduction}

India is growing market for automobile where biggest class of consumer is middle class family. Many automobile companies have already started research in HEV which has ability to use nonconvectional energy which is bestowed amply in India. HEV also become has economic choice for Indian consumer and for Indian environment. Government of India is also planning to give subsidy for HEV to motivate consumers to buy HEV. Fuel energy costs more than electric energy according to electric tariff plan. [1]

Design of HEV's components is began with studying drive cycle. Drive cycle pattern depends on road condition, road type, traffic density and driver`s behaviour [5].

There are different standard drive cycle available from different countries e.g. ECE-15, EUDC, EPA Federal Test [28]. These drive cycle data 
are used for vehicle emission analysis and for estimation of HEV`s components size. Standard drive cycles dose not reveal information like rate of acceleration \& deceleration and its power, peak power demand \& actual time of travelling [2].Efficient and economic design of HEV`s components cannot be done based on information and analysis from standard drive cycle. Design of motor, IC engine, battery is depended on load pattern. Different countries have different drive cycle pattern, so for actual information India road drive cycle must be measured in real travel time. Real time data of drive cycle are necessary to be measured and to reveal detailed information about drive cycle load pattern. Real time drive cycle measurement goes through natural environmental condition of all different type of roads, different type of road condition and different type of traffic condition which gives different drive cycle for different roads so it can be used for HEV`s components size estimation [3].

For the selection of power train configuration different power train configurations are available. All power train serves different purpose. There are different types of configuration of power train which are series design, parallel design, and series \& parallel design

Dynamic model of vehicle is used for modelling and simulation and it is used to calculate vehicle power requirement which is close to actual performance [6, 7].

Variety of drive cycle pattern has to be considered while HEV`s components initial sizing is determined. For initial sizing rule based theorem, different estimation method [27] and mean value models [29] are used. The optimum component size should be calculated by proper optimization method because direct initial sizing will not give a solution that works efficiently with different drive cycle patterns [8].

To select optimum component size optimization should be done. Certain constrain are set while optimization process is taking place.

Different optimization techniques can be used like swarm optimization, genetic algorithm optimization, multi objective genetic algorithm optimization and teaching and learning based optimization. TLBO method is never used for HEV`s components optimization.

Estimated component size can be optimized by GA. It uses derivative and it achieves single objective. It selects random values from population which is data derived from drive cycle. Fittest value is found from population.
Limitation of this method is it doesn't perform multi objective tasks [9]. Multi objective genetic algorithm is evolved method or modified method from GA. This method is able to satisfy multi objective laid down in single set of iteration flow. Iteration stops when fittest values are achieved, which is considered fittest among population and is solution $[10,11]$. Swarm optimization can be used to solve complex solution. It dose investigation of population by considering multi objectives as well as limitation set to those objectives. Control strategy for can also be optimized by swarm optimization technique [12, 13]. Teaching and learning based optimization method is recent development in field of optimization technique which is also inspired by nature of classroom working environment where teacher teach learners behave during study. For HEV`s components optimization this method can be useful because normally population size is high and multi objective supposed to be achieved while designing HEV`s components. In TLBO method learners which are drive cycle population learns to become best by comparing their data with each other and also modify them to achieve multiple objective and set control strategy.

After optimization of component size their performance parameters are checked and their running economy is also compared with conventional IC engine car which are present in India $[14,15]$.

Throughout the paper parallel configuration of $\mathrm{HEV}$ is considered which is explained in section 2. Information about real time drive cycle a method measurement on different Indian roads and its analysis cycle is done in section 3, Modelling of HEV`s components is done in section 4. In section 5, initial estimation of components is done by considering parameters of drive cycle. In section 6 initial estimation value is optimized by TLBO method which is new and never used for HEV's component size optimization and MOGA method to make comparison. Economical comparison is shown in section 7. Result of all method of optimization is shown in section 8 and it is concluded in section 9.

\section{System Configurations}

HEV`s components design is done for medium size vehicle. Various drive train configurations can be used for HEV. Selection of drive train pattern depends upon application. In this paper parallel drive train configuration is used. Parallel 
drive train requires less space compared to series configuration and is suitable for use in medium sized car. Series configuration is used for heavy duty application and its drive train requires additional generator space.

Figure 1 Shows block diagram of Parallel drive train configuration.

For parallel drive train configuration battery, fuel tank, IC engine, motor and inverter, splitter which splits load between IC engine and electric motor and this entire set of components are connected to the a load.

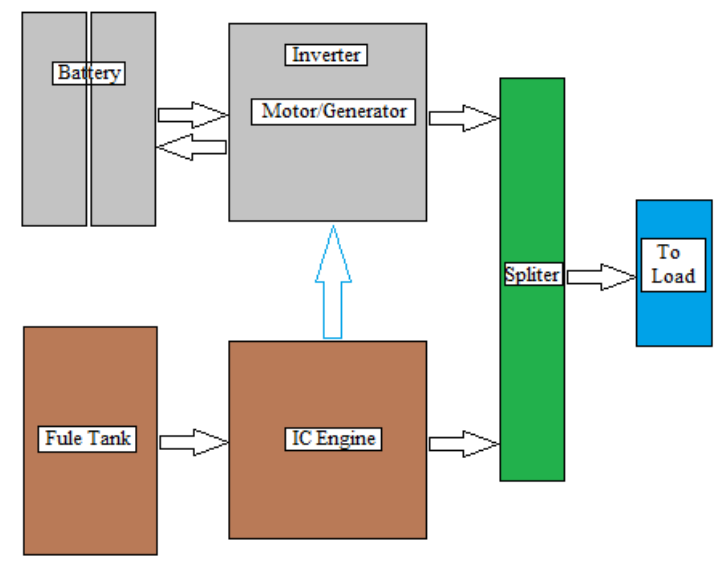

Figure 1: Parallel HEV

Here rating of IC engine and electric motor are $50 \%$ of load. Rating of IC engine can be chosen higher than $50 \%$ of load depending upon its maximum efficient point.

Dynamic model of HEV is used for modelling and analysis of vehicle parameters. Figure 2 Shows block diagram of dynamic model of HEV. As drive train component Lead-Ion battery, BLDC motor, diesel CRDi IC engine is selected.

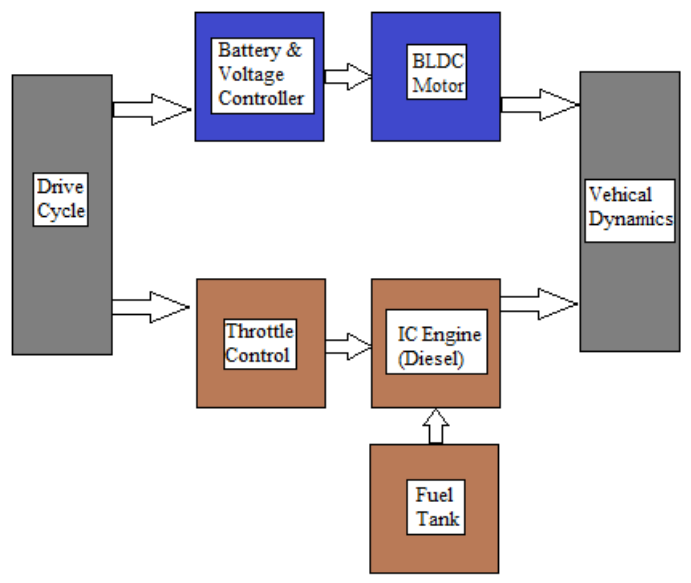

Figure 2: Dynamic Model of HEV

\section{Indian road drive cycle}

\subsection{Drive cycle measurement}

The driving cycle is sequence of vehicle operating condition i.e. idling, acceleration, cruise, creeping and declaration with respect to time for a given city, region or a country.

Indian roads are categorized in four ways which are (i) express highway (ii) national highway (iii) state highway (iv) urban roads/rural road [4].

So, the selection of population and road is very crucial while planning drive cycle measurement program. All type of Roads should be covered. Vehicle selection is also very crucial. Vehicle of similar rating should be selected as rating of $\mathrm{HEV}$ to be designed. Vehicle which is most economic while running is selected to start drive cycle measurement program. Table 1 shows parameters of vehicle to determine drive cycles.

Table 1: Vehicle Parameters

\begin{tabular}{|c|c|}
\hline Vehicle HP & $128 \mathrm{HP}$ \\
\hline $\begin{array}{c}\text { Vehicle RPM } \\
\text { Tractive Effort coefficient for } \\
\text { Indian roads }\end{array}$ & 0.4 to 0.5 \\
\hline Mass of Vehicle & $1300 \mathrm{Kg}$ \\
\hline $\begin{array}{c}\text { Rolling resistance coefficient } \\
\text { in this case }\end{array}$ & $\begin{array}{c}0.013(\mathrm{asph} \\
\text { road })\end{array}$ \\
\hline Height of CG from ground & $87 \mathrm{~cm}$ \\
\hline Effective radius of tire & $29 \mathrm{~cm}$ \\
\hline Distance between wheels & $268.5 \mathrm{~mm}$ \\
\hline
\end{tabular}

For the purpose of measurement of drive cycle medium sized car with diesel engine is used. Medium size cars are economical choice in India. Drive cycle measurement is carried out by android application which uses global positioning system by traveling in car. Data of time to speed were measured and plotted in android application and those were loaded in Microsoft excel. To collect legit drive cycle data the vehicle is driven in to natural environment.

\subsection{Characteristic of IRDC}

For different type of road the drive cycle parameters varies considerably as it can be observed from figure 3 . It can be observed that for express highway max speed and max HP is 
high but time of run is Less and from urban roads observed that acceleration and deceleration cycle is very high compared with Express highway but max HP and mac speed is low while national and state highway both requires high run time form HEV [16, 17].

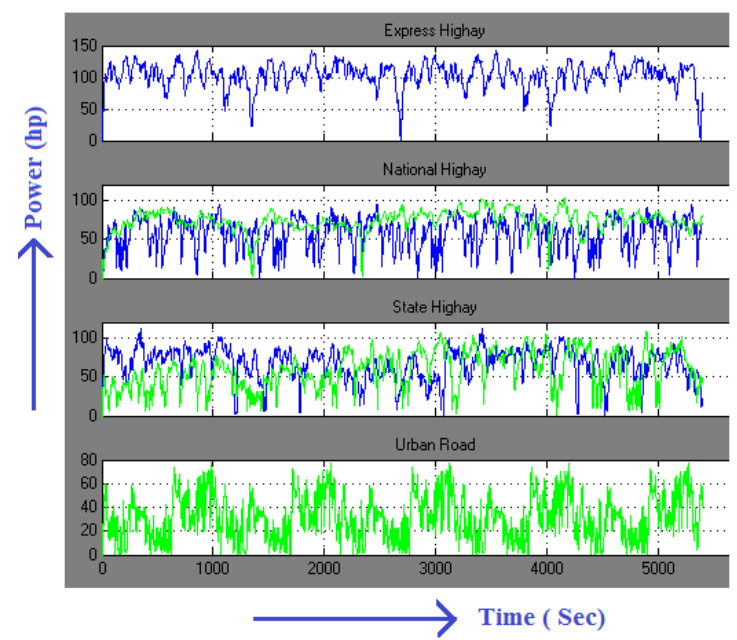

Figure 3: Drive Cycle

\subsection{Analysis}

Table 2 shows data of which are derived from real time drive cycle termed as drive cycle of different road (DC), average speed (AS), maximum speed (MS), Average Time (AT), Maximum Time (MT), total time(T) and distance (D). Data are categorized by means of road types E, N, S, C and U stands for express highway, national highway, state highway, state and national highway and urban road respectively.

It can be said that all drive cycle will have different requirements from power train. Express highways requires higher average HP and maximum HP while national and state highways requires vehicle to run for long time so design of HEV`s components should fulfil both load drive cycle characteristic.

Table 3 shows summery values of data from table 2 which enables to understand marginal difference in characteristics of different road drive cycle measured in real time.

\subsection{Vehicle Dynamics}

Vehicle dynamics are considered for calculation performance parameter of HEV. Vehicle's calculates performance parameter like its horsepower requirement, speed, torque, and acceleration \& deceleration power can be determined by vehicle dynamics.
Table 2: Mean Values of Drive Cycle Parameters

\begin{tabular}{|c|c|c|c|c|c|c|}
\hline DC & AS & MS & AT & MT & T & D \\
\hline \multicolumn{7}{|c|}{ Express Highway } \\
\hline E & 106 & 147 & 103 & 143 & 45 & 80 \\
\hline \multicolumn{7}{|c|}{ National Highway } \\
\hline N1 & 57 & 97 & 57 & 95 & 23 & 22 \\
\hline N2 & 83 & 38 & 81 & 135 & 209 & 220 \\
\hline N3 & 63 & 135 & 62 & 122 & 95 & 100 \\
\hline N4 & 81 & 133 & 79 & 130 & 25 & 33 \\
\hline N5 & 70 & 105 & 68 & 102 & 140 & 170 \\
\hline \multicolumn{7}{|c|}{ State Highway } \\
\hline S1 & 66 & 115 & 64 & 112 & 51 & 60 \\
\hline S2 & 60 & 115 & 58 & 112 & 171 & 171 \\
\hline S3 & 61 & 119 & 60 & 116 & 27 & 27 \\
\hline S4 & 79 & 141 & 77 & 138 & 50 & 65 \\
\hline \multicolumn{7}{|c|}{ State \& National Highway } \\
\hline C1 & 78 & 131 & 76 & 128 & 76 & 98 \\
\hline C2 & 76 & 126 & 74 & 123 & 186 & 235 \\
\hline \multicolumn{7}{|c|}{ Urban Road } \\
\hline U1 & 26 & 63 & 28 & 60 & 23 & 9 \\
\hline U2 & 32 & 79 & 32 & 77 & 17 & 9 \\
\hline Avg & $\mathbf{7 0}$ & $\mathbf{1 1 4}$ & $\mathbf{6 8}$ & $\mathbf{1 1 8}$ & $\mathbf{8 5}$ & $\mathbf{9 9}$ \\
\hline
\end{tabular}

Table 3: Drive cycle summary

\begin{tabular}{|c|c|c|c|c|c|c|}
\hline DC & AS & MS & AT & MT & T & D \\
\hline E & 106 & 147 & 103 & 143 & 45 & 80 \\
\hline N & 63 & 101 & 62 & 98 & 81 & 96 \\
\hline S & 71 & 120 & 69 & 117 & 118 & 147 \\
\hline U & 29 & 71 & 30 & 68 & 20 & 9 \\
\hline
\end{tabular}

$\mathrm{F}_{\mathrm{t} \text { total }}=\mathrm{F}_{\mathrm{t} \max }+\mathrm{F}_{\mathrm{r}}+\mathrm{F}_{\mathrm{w}}+\mathrm{F}_{\mathrm{g}}$

$\mathrm{F}_{\mathrm{t} \text { total }}$ is total force required at front axle which considers resistance forces of road and car to calculate actual force required by car. From force torque, speed and horse power are calculated which are shown in table 2 and 3. 


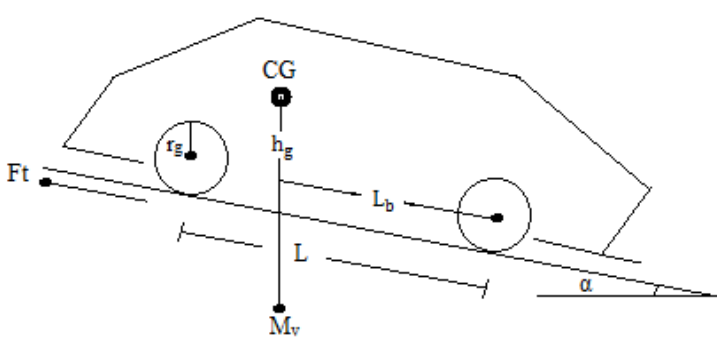

Figure 4: Vehicle dynamics

$\mathrm{F}_{\mathrm{t} \max }=\mu \mathrm{W}_{\mathrm{f}}=$

$\left[\frac{L_{b}}{L} M_{v} g \cos \alpha-\frac{h_{g}}{L}\left(F_{t \text { max }}-F_{r}\left(1-\frac{r_{d}}{h_{g}}\right)\right)\right] \mu$

Parameters of resistance force are calculated as [19]

Rolling resistance force

$\mathrm{F}_{\mathrm{r}}=\operatorname{Pf}_{\mathrm{r}} \operatorname{Cos} \alpha$

Aaerodynamic drag force

$F_{w}=\rho A_{f} C_{D}(V+V w)^{2}$

Gradient Resistance force

$\mathrm{F}_{\mathrm{g}}=\mathrm{M}_{\mathrm{v}} \mathrm{g} \sin \alpha$

[19]

Figure 4 shows parameters of dynamic vehicle used for equations.

This resistance are summed up to get actual power used during vehicle dynamics calculation.

\section{Modelling of HEV's components}

From IRDC analysis battery kilo watt requirement, hour requirement, size of motor, size of IC engine and fuel tank is determined. The seizing is done for parallel configuration of HEV which is simulated in MATLAB Simulink. Data taken from table 2 are average HP and maximum HP to determine average power require by motor and IC engine and peak power required by the same and deceleration power to estimate power of battery and its recharging from deceleration energy. From those mean value of each parameter is considered [28]. All component size estimation and its optimization will be tested in MATLAB Simulink model. Parallel HEV model is modelled in MATLAB Simulink.

Brushless DC Motor, Lead-Ion Battery, IC Engine same as motor rating is selected as component of HEV.
For simulation and modelling of parallel configuration of $\mathrm{HEV}$, modelling equations are mentioned below.

1. Battery charging, discharging model [21]

\section{- Discharge Voltage Status}

$\mathrm{V}_{\mathrm{OC}}=\mathrm{E}_{\mathrm{o}}-\mathrm{R} \times \mathrm{i}-\mathrm{K} \frac{Q}{Q-i t}(\mathrm{i} \mathrm{t}+\mathrm{i})+\operatorname{Exp}(\mathrm{t})$

- Charging Voltage Status

$\mathrm{V}_{\text {charge }}=\int\left(\frac{d w}{d t_{(<0)}} \times \frac{w}{V} \times V_{\text {total }} \times C_{c c}\right) \mathrm{dt}$

- SOC Calculation [22]

$\mathrm{Q}_{\mathrm{ut}}=\mathrm{V} \times \mathrm{I} \times(\mathrm{T})=\mathrm{VIH}$

$\mathrm{Q}_{\mathrm{ut}}=\mathrm{WH}$

$\mathrm{Q}_{\mathrm{u}}=\mathrm{WH}-\int_{0}^{t} i(t) d t$

$\mathrm{K}=\frac{Q_{u}}{Q_{u t}} \times 100 \%$

\section{Brushless DC motor model [23]}

Modelling equations of brushless DC motor

$\mathrm{I}_{\mathrm{S}}=\frac{P}{V}$

$\mathrm{T}=\frac{\text { Watt }}{2 \pi \times W_{\text {sync }}}$

$\mathrm{L}_{\mathrm{st}}=\frac{T}{2 N_{m} N B_{g} R_{r 0} I_{s}}$

$\mathrm{T}_{\mathrm{L}}=2 \mathrm{~L}_{\mathrm{st}} \mathrm{N}_{\mathrm{m}} \mathrm{N} \mathrm{B}_{\mathrm{g}} \mathrm{R}_{\mathrm{r} 0} \mathrm{I}_{\mathrm{s}}$

$\mathrm{L}_{\mathrm{g}}=\frac{2 \pi \mu_{0}, R_{r 0}, L_{s t} N^{2}}{g+\frac{l_{m}}{\mu_{r} C_{\emptyset}}}$

$\mathrm{C}_{\Phi}=\frac{A_{m}}{A_{g}} \cong 1$

$\mathrm{T}=\mathrm{J} \frac{d \omega_{m}}{d t}+T_{L}+B \omega_{m}$

$\omega_{m}=\int \frac{T-T_{L}}{J}$

$\mathrm{T}_{\mathrm{m}}=\frac{P}{\omega_{m}}$

\section{Throttling model [24]}

Throttle model is done by making look up table from standard throttle opening to fuel output graph of IC engine.

\section{IC engine model [25]}

$\mathrm{B}_{\mathrm{HP}}=\frac{\mathrm{P} \times \mathrm{A} \times \mathrm{L} \times \mathrm{N} \times \mathrm{n}}{60}$

$\mathrm{P}_{\mathrm{i}}=$ Indicated mean effective pressure

$\mathrm{A}=$ Bore area $=0.05$

$\mathrm{L}=$ Length of displacement $=0.065$ 
$\mathrm{N}=$ R.P.M. $=6000$

$\mathrm{n}=$ Cylinder $=4$

\section{Fuel tank model}

By calorific value model

Total energy in car,

Diesel calorific value $\mathrm{D}_{\text {cal }}=46000$

Tank capacity $\mathrm{T}_{\mathrm{c}}=22.5$

Time (sec) $\mathrm{T}=3600$

$\mathrm{D}_{\text {cal }} \times \mathrm{T}_{\mathrm{c}} \times \mathrm{T}=3.726 \times 10^{9}$ Calorie

From this simulation model parameters like SOC\%, fuel consumption, battery consumption torque \& horsepower production will be analysed.

\section{Influence of drive cycle in HEV`s components sizing}

The main component of HEV`s power train are battery storage, power rating of electric machine and size and rating of IC engine and it's fuel tank capacity [20]. All this components mainly determines initial cost of HEV's power train. Running cost is determined by fuel/battery power consumption.

To determine components size of HEV first step is to collect data of real time drive cycles of roads where $\mathrm{HEV}$ is to be driven.

Influence parameter for battery ampere-hour rating is determined by how long vehicle has to be travelled which average distance of different is charging station and acceleration power requirement of motor.

Similarly size of IC engine and motor is determined by average power and peak power required to fulfil drive cycle load requirement [19].

Deceleration energy determines rating recharging circuit which should be capable of holding and harvesting deceleration power.

Deceleration and acceleration power is higher in urban roads and state highway while it is considerably less in express highway.

From figure 5 and 6 initial component size can be estimated. Initial estimation is done to begin designing process of HEV`s component.

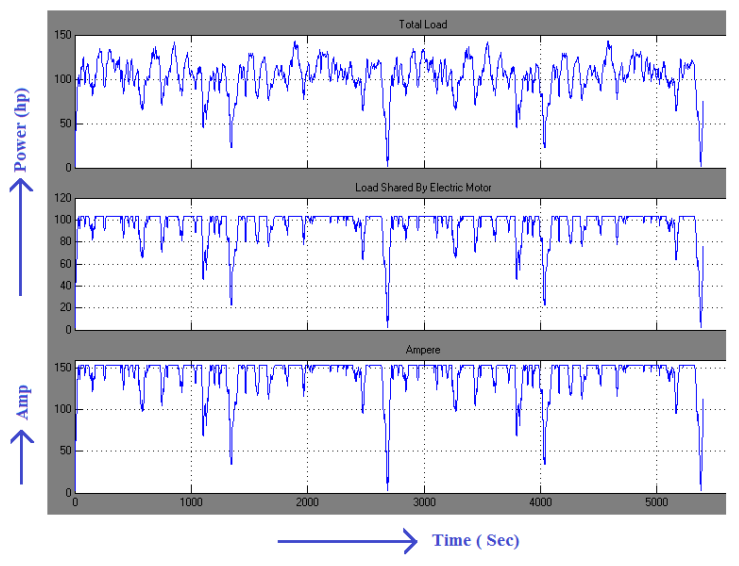

Figure 5: Electric Motor Power and Ampere

Initial estimation of components is derived without keeping any constraint by simply finding means of drive cycle parameters. Initial sizing is done by mean value method and results are;

Motor rating $=60 \mathrm{hp}$

IC engine rating $=60 \mathrm{hp}$

Battery rating $=22.7 \mathrm{kw}$

Fuel Tank $=22$ lit.

Initial sizing is not done by any algorithm or any designing method but simply by considering the influence of drive cycle on HEV's component sizing and from table 3 which shows mean load demand [27].

From this initial sized data of component, optimization will be done with consideration of constraints.

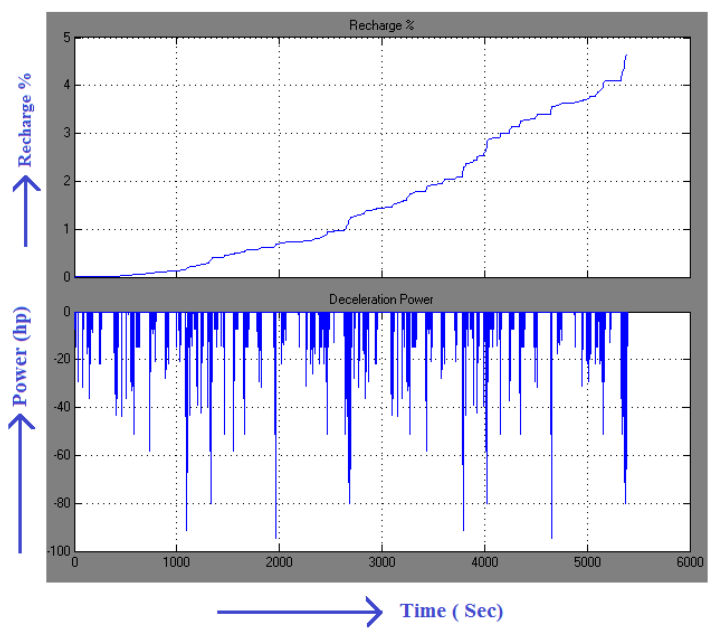

Figure 6: Recharge of Battery and Deceleration Energy 
Table 5: Rating from result of optimization

\begin{tabular}{|l|l|l|l|}
\hline $\begin{array}{l}\text { Optimization } \\
\text { Method(Final } \\
\text { Rating) }\end{array}$ & $\begin{array}{l}\text { Motor } \\
\text { (HP) }\end{array}$ & $\begin{array}{l}\text { IC } \\
\text { Engine } \\
\text { (HP) }\end{array}$ & $\begin{array}{l}\text { Battery } \\
\text { Rating } \\
\text { (kw) }\end{array}$ \\
\hline Mean Value & 60 & 60 & 22.7 \\
\hline TLBO & 45 & 45 & 21.5 \\
\hline MOGA & 50 & 50 & 21.5 \\
\hline
\end{tabular}

\section{Economy}

Economy of running HEV is based on electricity and fuel prices on year 2015. It is calculated in terms of $\mathrm{Rs} / \mathrm{km}$. Rs $/ \mathrm{km}$ for convectional IC engine and HEV which contains design component are calculated [27]. How much money needed to be spent for kilometre ride for any drive cycle is compared in result.

Table 6: Running cost

\begin{tabular}{|l|l|l|}
\hline Car Type & Rs/KM & Road \\
\hline IC Engine & 3.005 & Express highway \\
\hline HEV & 1.45 & Express highway \\
\hline
\end{tabular}

HEV have lower running cost as compared to conventional IC engine type car which could be prime factor to motivate Indian consumer to buy HEV technology based car.

\section{Results}

Table 7, 8, 9 shows result of different optimization method. Component sized from mean value method shows it to be least efficient among three.

Optimization by TLBO shows $4 \%$ in rpm drop which means $4 \%$ less acceleration than mean value method of component design while it shows efficient IC engine operation which is less efficient component in any HEV.

By results of TLBO optimization method with MOGA optimization method it shows result came from TLBO are efficient than MOGA but it shows drop of rpm of $1.5 \%$ compared with MOGA.

TLBO method reduces component size to $25 \%$ and with MOGA method to $20 \%$ compared with results from mean value method.

These optimized component size were put in to different drive cycle condition where none of the result shows any variation in its performance and TLBO is able to sustain all drive cycle characteristics by dropping 4\% in RPM even with $25 \%$ less in HP rating.

Table 7: For state highway

\begin{tabular}{|l|l|l|l|l|}
\hline $\begin{array}{l}\text { Designing } \\
\text { Method }\end{array}$ & HP & $\begin{array}{l}\text { Battery } \\
\text { SOC \% }\end{array}$ & $\begin{array}{l}\text { Fuel } \\
\text { Left } \\
\text { \% }\end{array}$ & $\begin{array}{l}\text { RPM } \\
\text { Drop } \\
\text { \% }\end{array}$ \\
\hline $\begin{array}{l}\text { Mean Value } \\
\text { Result }\end{array}$ & 120 & 76.08 & 40.12 & 0 \\
\hline $\begin{array}{l}\text { MOGA } \\
\text { Optimization } \\
\text { Result }\end{array}$ & 98 & 77.26 & 44.66 & 2.5 \\
\hline $\begin{array}{l}\text { TLBO } \\
\text { Optimization } \\
\text { Result }\end{array}$ & 90 & 78.7 & 51.12 & 4 \\
\hline
\end{tabular}

Table 8: For urban highway

\begin{tabular}{|l|l|l|l|l|}
\hline $\begin{array}{l}\text { Designing } \\
\text { Method }\end{array}$ & $\begin{array}{l}\text { H } \\
\text { P }\end{array}$ & $\begin{array}{l}\text { Battery } \\
\text { SOC \% }\end{array}$ & $\begin{array}{l}\text { Fuel } \\
\text { Left } \\
\text { \% }\end{array}$ & $\begin{array}{l}\text { RPM } \\
\text { Drop } \\
\text { \% }\end{array}$ \\
\hline $\begin{array}{l}\text { Mean } \\
\text { Value } \\
\text { Result }\end{array}$ & 120 & 98.06 & 99.47 & 0 \\
\hline $\begin{array}{l}\text { MOGA } \\
\text { Result }\end{array}$ & 98 & 98.19 & 99.51 & 2.5 \\
\hline $\begin{array}{l}\text { TLBO } \\
\text { Result }\end{array}$ & 90 & 98.25 & 99.57 & 4 \\
\hline
\end{tabular}

Table 9: For express highway

\begin{tabular}{|l|l|l|l|l|l|}
\hline $\begin{array}{l}\text { Designing } \\
\text { Method }\end{array}$ & HP & \multicolumn{2}{|l|}{$\begin{array}{l}\text { Battery } \\
\text { SOC \% }\end{array}$} & $\begin{array}{l}\text { Fuel } \\
\text { Left } \\
\text { \% }\end{array}$ & $\begin{array}{l}\text { RPM } \\
\text { Drop } \\
\text { \% }\end{array}$ \\
\hline $\begin{array}{l}\text { Mean Value } \\
\text { Result }\end{array}$ & 120 & 92.64 & 40.12 & 0 \\
\hline $\begin{array}{l}\text { MOGA } \\
\text { Optimization } \\
\text { Result }\end{array}$ & 98 & 92.9 & 90.33 & 2.5 \\
\hline $\begin{array}{l}\text { TLBO } \\
\text { Optimization } \\
\text { Result }\end{array}$ & 90 & 92.81 & 51.12 & 4 \\
\hline
\end{tabular}

\section{Conclusion}

Drive cycle is measured for Indian road that revealed its numerous characteristics. There is major variation in drive cycle for different road type. From cycle data component size were estimated and optimized with new method which 
is TLBO. To observe TLBO method's effectiveness it was compared with MOGA method of optimization. Results were simulated in MATLAB on with dynamic model of vehicle and modelling of parallel HEV`s components. Component selected by different optimization methods were put through different drive cycle and it did show that optimization done by TLBO method selects component size that is less than other two component size result derived with different methods. TLBO component rating is less than other two but still it is able to sustain different drive cycle load characteristics by only $4 \%$ drop in RPM. TLBO method proves to be optimizing HEV component more effectively because it has capability to modify data that suits different criteria. By optimal reduction in HEV component size with TLBO method the running cost of vehicle is reduced up to $50 \%$ by reducing rating of component. TLBO method is very effective tool of optimization of HEV for versatile drive cycle characteristics as Indian road have.

\section{References}

[1] Vaibhav Aaradhi, Ketaki Gaidhani, Plug In Hybrid Electric Vehicle- Indian Transport Sector Perspective,, ISSN 2229-5518, International Journal of Scientific \& Engineering Research,2013

[2] Sanghpriya H. Kamble, Tom V. Mathew, G.K. Sharma, Development of real-world driving cycle: Case study of Pune, India,ISSN 13969209,Elsevier Science,2009.

[3] Varsha Shah, Patel Pritesh, Patel Sagar, Prasanta Kundu Ranjan, Maheshwari, Measurement of Real Time Drive Cycle for Indian Roads and Estimation of Component Sizing for HEV using LABVIEW, World Academy of Science, Engineering and Technology 582011

[4] Lok Sabha Secretariat, National Highways Development Project: An Overview, parliament Library and reference, research, documentation and information service, August/2013

[5] Staackmann, M.Liaw, B.Y., Dynamic driving cycle analyses using electric vehicle time-series data, Energy Conversion Engineering Conference 0-7803-4515-0,1997

[6] Chen, K.,Villeneuve-d"Ascq, Lhomme, W., Bouscayrol, A., Berthon, A., Comparison of two series-parallel Hybrid Electric Vehicles focusing on control structures and operation modes, Vehicle Power and Propulsion Conference,2009

[7] Xin Li; Dept. of Electr. \& Computer Eng. Concordia Univ., Montreal, QC ; Williamson, S.S., Comparative Investigation of Series and Parallel Hybrid Electric Vehicle (HEV) Efficiencies Based on Comprehensive Parametric Analysis, Vehicle Power and Propulsion Conference, 2007

[8] Massimo Ceraolo, Antonio di Donato, and Giulia Franceschi, A General Approach to Energy Optimization of Hybrid Electric Vehicles, IEEE transactions on vehicular technology, vol. 57, no. 3, may 2008

[9] Lei Zhang, David G. Dorrell,, Genetic Algorithm Based Optimal Component Sizing For an Electric Vehicle, IEEE, 2013

[10] Bufu Huang, Zhancheng Wang and Yangsheng $\mathrm{Xu}$, Multi-Objective Genetic Algorithm for Hybrid Electric Vehical Parameter Optimization International Conference on Intelligent Robots And Systems, 2006

[11] Thomas J. Boehme, Benjamin Frank, Markus Schori and Torsten Jeinsch, Multi-Objective Optimal Powertrain Design of Parallel Hybrid Vehicles with Respect to Fuel Consumption and Driving Performance, European Control Conference, 2014

[12] Chirag Desai, Student Member, IEEE, and Sheldon S. Williamson, Member, IEEE, Particle Swarm Optimization for Efficient Selection, Of Hybrid Electric Vehicle Design Parameters, Power and Energy

Lab, 2010

[13] Omar Hegazy, Student Member, IEEE, and Joeri Van Mierlo, Particle Swarm Optimization for Optimal Powertrain Component Sizing and Design of Fuel Cell Hybrid Electric Vehicle, 12th International Conference on Optimization of Electrical and Electronic Equipment, 2010

[14] R.V. Rao, V.J. Savsani, D.P. Vakharia, Teaching-learning-based optimization: A novel Method for constrained mechanical design Optimization problems, Computer-Aided Design, 2015

[15] David L. González-Álvarez, Miguel A. VegaRodríguez, Juan A. Gómez-Pulido, And Juan M. Sánchez-Pérez, Multi-objective Teaching-Learning-Based Optimization (MOTLBO) for Motif Finding, International Symposium on Computational Intelligence and Informatics, 2014 
[16] Sanjeev SINHA, Ravindra KUMAR, Driving Cycle Pattern for Cars in Medium Sized City of India, Proceedings of the Eastern Asia Society for Transportation Studies, Vol.9, 2013

[17] Atyam mukherjee, Statistical analysis of the road network of India, Indian Academy of

[18] Mehrdad Ehsani,Yimin Gao,Sebastien E. Gay,Ali Emadi, Modern Electric Hybrid Electric, and Fuel Cell Vehicles, Fundamentals, Theory, and Design,Ch 2,Crc Press,2000

[19] J. Kwon, J. Kim, E. Fallas, S. Pagerit, and A. Rousseau, Impact of Drive Cycles on PHEV Component Requirements, SAE International, 2008

[20] Ayman Moawad, Gurhari Singh, Simeon Hagspiel, Mohamed Fellah, Aymeric Rousseau, Impact of Real World Drive Cycles on PHEV Fuel Efficiency and Cost for Different Powertrain and Battery Characteristics, EVS24,2009

[21] Olivier Tremblay1, Louis-A. Dessaint, Experimental Validation of a Battery Dynamic Model for EV Applications, EVS 24,2009

[22] Sabine Piller, Marion Perrin,Andreas Jossen,Methods for state-of-charge determination and their applications, Journal of Power Sources, 2001

[23] T.J.E. Miller, Brushless Permanent-Magnet and Reluctance Motor Drives, Oxford Science Publication, 1989

[24] Willard W. Pulkrabek, Engineering Fundamentals of the Internal Combustion Engine Ch3,Prentice Hall,2003

[25] Willard W. Pulkrabek, Engineering Fundamentals of the Internal Combustion Engine Ch5,Prentice Hall,2003

[26] Kalyanmoy Deb., Multi-Objective Optimization Using Evolutionary Algorithm,Ch 3,Wiley,2010

[27] Kumari M, Thakura, P.R. Badodkar, D.N. Design and estimation of drive train components of Hybrid Electric Vehicle, Non-Conventional Energy (ICONCE), 2014

[28] Sanjeev SINHA, Ravindra KUMAR, Driving Cycle Pattern for Cars in Medium Sized City of India, Proceedings of the Eastern Asia Society for Transportation Studies, Vol.9, 2013

[29] Clement Fauvel, Vikesh Napal, Aymeric Rousseau, Medium and Heavy Duty Hybrid Electric Vehicle Sizing to Maximize Fuel
Consumption Displacement on Real World Drive Cycles, EVS26, May 6-9-2012

\section{Authors}

Dr. Varsha Shah received Master of Engineering degree in Power System from SVRCET (Surat, Gujarat) in 1986. PhD. Degree from SVNIT (Surat, Gujarat). Currently she is Associate Professor at SVNIT in electrical department. Field of Research: $\mathrm{HEV}$, EV, energy storage technology, power system and electrical drives.

Vishal Sanjaybhai Parekh received Master of Engineering degree in Power Electronics and Electrical Drive from MEFGI (Rajkot, Gujarat) in 2012. Currently he is Research Head at ASPERO research (Rajkot, Gujarat). Field of research: Power electronics, electric drive, hybrid electric vehicle, embedded system. 